\title{
A UTILIZAÇÃO DE PRODUÇÕES CINEMATOGRÁFICAS NA FORMAÇÃO INICIAL DE PROFESSORES
}

\author{
THE USE OF FILM PRODUCTION IN INITIAL TEACHER TRAINING
}

\author{
Valdênia Rodrigues Fernandes Eleotério \\ Mestre \\ Universidade Católica Dom Bosco - UCDB \\ Campo Grande, MS - Brasil \\ valdeniaeleoterioufms@gmail.com
}

\begin{abstract}
Resumo: Esse artigo versa sobre formação inicial de licenciados e prática pedagógica. O objetivo geral da pesquisa foi analisar as implicações que a utilização de produções cinematográficas na formação inicial de professores traz a sua prática pedagógica. A pesquisa é qualitativa, o instrumento utilizado para a coleta de dados foi a entrevista semiestruturada. Os sujeitos da pesquisa são dois professores que atuam nos anos iniciais do ensino fundamental em uma instituição pública da região centro-oeste. Os principais resultados indicam que a utilização de filmes na formação inicial desses professores trouxeram implicações positivas uma vez que os docentes utilizam esse recurso didático-pedagógico cotidianamente em suas práticas como um possível caminho para fomentar a aprendizagem, a inclusão e a resolução de conflitos presentes em sala de aula.
\end{abstract}

Palavras-chave formação inicial de professores; produções cinematográficas; práticas pedagógicas.

Abstract: This is article deals winth initial training and pedagogical practice. The general objective of the research was to analyze the implications that the use of film productions in the initial training of teachers brings to their pedagogical practice. The research is qualitative. The instrument used for date collection was the semi-structures interview. The research subjects are two professors who work in the early years of elements school in a public institution in the Midwest region. The main results indicate that the use of films in the initial training of these teachers brought positive implications since teachers use this didacticpedagogical resource on a daily basis in their practices as possible way to foster learnig, inclusion and conflict resolution present in the classroom.

Keywords: initial teacher training; cinematografhic productions; pedagogical practices.

ELEOTÉRIO, Valdênia Rodrigues Fernandes. A utilização de produções cinematográficas na formação inicial de professores. Cadernos de Pós-graduação, São Paulo, v. 20, n. 2, p. 90-98, jul./dez. 2021. Disponível em: https://doi.org/10.5585/cpg.v20n2.20216. 
Introdução

A formação de professores e a prática docente são temas de pesquisas científicas, notícias em jornais e revistas nacionais e internacionais. Um número significativo desses estudos e debates destaca que o primeiro ano de atuação do professor é permeado pelo anseio em desenvolver práticas pedagógicas que fomente a aprendizagem, pelo medo de como será recebido pelos alunos e colegas que já atuam na profissão, pelas tensões já presenciadas no período de estágio no exercício da docência, como, a falta de recursos materiais que em alguns cenários comprometem o processo de ensino.

Diante do contexto apresentado, esse artigo nasce de reflexões durante o período de seis meses em que desenvolvi um projeto de extensão, em uma escola pública, situada na região centrooeste do Brasil.

No cotidiano escolar percebi que dois professores(as) utilizavam com certa frequência os filmes como recurso pedagógico em sala de aula. Essa tomada de decisão dos professores em alguns momentos geravam críticas negativas, desmotivadoras dos colegas de profissão, fatores que não se tornaram um impeditivo para que esses profissionais continuassem transformando o quadro branco em tela de cinema.

Diante do contexto apresentado o objetivo geral da pesquisa foi analisar as implicações que a utilização de produções cinematográficas na formação inicial de professores traz a sua prática pedagógica. E os objetivos específicos foram; investigar se os filmes fizeram parte da formação inicial dos professores, pesquisar os critérios utilizados pelos professores na escolha dos filmes utilizados em sala de aula e compreender como os professores abordam as temáticas centrais dos filmes em suas práticas pedagógicas.

\section{O caminhar na pesquisa}

Quando o pesquisador decide desenvolver uma investigação, ele busca respostas as suas indagações, inquietações. Para que isso ocorra de maneira ética e coerente ele precisa planejar a metodologia "o caminho do pensamento e a prática exercida na abordagem da realidade" (MINAYO, 2002, p. 16).

Sabemos, que a pesquisa na área de ciências humanas, tem um importante papel social, pois ela visa compreender os sujeitos e suas ações em relação a si, ao outro e ao universo que os cercam de maneira interdisciplinar, buscando desenvolver nesses atores sociais o senso crítico, a reflexão, motivando-os a produzir novos conhecimentos para enfrentar os desafios que surgem cotidianamente na sociedade que estão inseridos. 
Essa pesquisa é classificada no campo da ciência como qualitativa, por "trabalhar com o universo de significados, motivos, aspirações, crenças, valores e atitudes, o que corresponde a um espaço mais profundo das relações, dos processos, dos fenômenos que não podem ser reduzidos por operacionalização de variáveis" (MINAYO, 2002, p. 21-22).

O instrumento utilizado para a coleta de dados foi a entrevista semiestruturada. A escolha se deu por entender que o diálogo faz emergir de forma espontânea informações significativas que talvez não fossem obtidas com perguntas fechadas padronizadas. Para Manzini (2003, p. 4), esse instrumento "é indicado quando a natureza da informação se tratar de fenômeno que ficaria difícil ou impossível de ser observado".

A pesquisa foi desenvolvida no mês de outubro, do ano de 2019. Os sujeitos foram dois professores(as), que exercem a docência nos anos iniciais do ensino fundamental, em uma instituição da rede estadual de ensino localizada em um município da região centro-oeste, Brasil. Para respeitar o sigilo de suas identidades serão denominados na pesquisa por Clara, 50 anos, formados em pedagogia, atua na profissão há 21 anos e Paulo, 48 anos, formado em educação física, atua na profissão há 18 anos.

As entrevistas foram realizadas presencialmente, o tempo de duração variou entre quarenta e cinco minutos e uma hora. Antes de começar as interlocuções, expliquei a cada sujeito individualmente a relevância da assinatura do Termo de Consentimento Livre e Esclarecido para pesquisador e entrevistado.

\section{Formação inicial de professores por meio de produções cinematográficas}

O Brasil possui universidades públicas e privadas que utilizam como recurso didático-pedagógico na formação inicial de acadêmicos dos cursos de licenciatura e bacharelado filmes, músicas e documentários entre outros. Geralmente essas produções culturais são escolhidas para ensinar componentes curriculares e despertar a criticidade do futuro professor sobre pautas raciais, de gênero, religiosas e política entre outras que podem estar presentes nas relações escolares. De acordo com Lima (2001)

o filme, como instrumento de reflexão pedagógica, pode representar um excelente mecanismo de formação de docentes. A intencionalidade da atividade na sala de aula, a clareza dos objetivos, o debate a partir dos problemas e das possibilidades apresentadas, o estudo crítico do enredo do filme, bem como a articulação com a realidade dos professores, no tempo histórico e no espaço, constituirão uma oportunidade de diálogo e ressignificação do trabalho do professor. (LIMA, 2001, p. 80).

Porém, alguns autores pontuam que a docência é uma atividade complexa e a aquisição dos 
saberes necessários para mediar conflitos e o domínio dos elementos didáticos-técnicos para realizar práticas pedagógicas de acordo com a realidade vivida no chão da escola com significado só serão alcançados com a prática cotidiana.

Segundo Pimenta (2008, p. 20) "o desafio posto aos cursos de formação inicial é o de colaborar no processo de passagem dos alunos de seu ver o professor como aluno ao seu ver-se como professor. Isto é, de construir a sua identidade de professor". O autor pontua que nenhum aluno sai da graduação com a identidade docente formada, porque ela é construída em um processo continuo.

Gradativamente o professor vai se reconhecendo e sendo reconhecido na profissão pela sua atuação, pelas mudanças ocorridas de acordo com as exigências das instâncias educacionais superiores e da comunidade escolar. Pois a docência é uma das atividades profissionais mais regulada e também desvalorizada social e financeiramente.

Os debates sobre a formação e a profissão docente são inesgotáveis fontes de pesquisas, esse ofício é retratado até mesmo no cinema como no filme "A sociedade dos poetas mortos" de Tom Schulman. A produção cinematográfica conta a história fictícia de um professor de literatura que utilizava a poesia como expressão artística para desenvolver práticas pedagógicas que hoje podem ser analisadas como "libertadoras" segundo a perspectiva freiriana, uma atitude considerada atípica para os rígidos padrões sociais norte-americanos da década de 50. Frequest (2013) explica que:

\begin{abstract}
A crença no cinema e na sua possibilidade de intensificar as invenções de mundos, ou seja, da possibilidade que o cinema tem de tornar comum o que não nos pertence, o que está distante, as formas de vida e as formas de ocupar os espaços e habitar o tempo. A segunda crença é na escola, como espaço em que o risco dessas invenções de tempo e espaço é possível e desejável. Isto não significa pensar no belo, no conforto ou na harmonia. Significa que é possível inventar espaços e tempos que possam perturbar uma ordem dada, do que está instituído, dos lugares de poder. (FRESQUET, 2013, p. 25).
\end{abstract}

Compreendo que a utilização de filmes na formação inicial e continuada de professores traz a possibilidade de contribuir com o processo reflexivo acerca de problemas sociais no espaço onde a universidade está inserida e/ou questões globais como a crise econômica que gera um alto índice de desemprego no país, a corrupção política que resulta no desvio e corte de verbas da saúde e educação entre tantas outras. Segundo Silva (2007)

o cinema é tido como um dos mais poderosos meios de comunicação de massa do século XXI, razão pela qual não se pode ignorar a força, nem malbaratar o grande poder de educação, oferecido por esse meio. Os filmes são uma fonte de conhecimento e se propõem, de certa forma, a "reconstruir a realidade". A linguagem cinematográfica tem o mérito de permitir que a relação entre filmes e imaginário social aconteça. (SILVA, 2007, p. 50-51). 
Mesmo o cinema sendo considerado um meio de comunicação de massa e um recurso pedagógico que fomenta o processo de ensino/aprendizagem existe uma significativa parcela da população a nível mundial que ainda não teve acesso a esse bem cultural, o que é lamentável.

Para Silva (2013) as produções cinematográficas podem contribuir no contexto educacional para despertar o desejo de revelar sentimentos, medos, desejos, inquietações sobre problemas cotidianos comprometendo o processo de ensino/aprendizagem, interferindo nas interações, na aquisição de conhecimentos. O pensamento de Silva (2013) vai ao encontro de Fresquet (2013) quando ressalta que

\footnotetext{
os possíveis vínculos entre o cinema e a educação se multiplicam a cada momento, a cada nova iniciativa ou projeto que os coloca em diálogo. Fundamentalmente, trata-se de um gesto de criação que promove novas relações entre as coisas, pessoas, lugares e épocas. De fato o cinema nos oferece uma janela pela qual podemos nos assomar ao mundo para ver o que está lá fora, distante do espaço ou no tempo, para ver o que não conseguimos ver com nossos próprios olhos de modo direto. (FRESQUET, 2013, p. 19).
}

Como podemos perceber os filmes são recursos pedagógicos relevantes na formação inicial e continuada de alunos e professores por abrir espaços para futuros debates, ligar o fio condutor entre ficção e realidade com o uso de múltiplas linguagens e diferentes perspectivas.

A sua utilização também deve ser pensada de forma a despertar a criticidade para romper com padrões hegemônicos culturais e sociais eurocentricamente padronizados enraizados há séculos nas instituições abrindo caminho para que a diversidade de povos e raças presentes nesses espaços seja acolhida, ouvida, integrada, valorizada. A seguir apresentaremos os resultados e as discursões obtidos por meio da entrevista semiestruturada.

\section{Resultados e discursões}

A primeira indagação feita aos sujeitos da pesquisa foi; As produções cinematográficas fizeram parte da sua formação inicial? O professor Paulo responde:

Concluí minha graduação em educação física no ano de 2004, em uma universidade privada e os professores constantemente utilizavam filmes, documentários e músicas nas aulas, mas de uma forma técnica, maçante, cartesiana para visualizarmos os movimentos, compreendêssemos o ritmo em que aquele exercício deveria ser executado. Quase não havia interação e nem incentivo para que isso acontecesse. O que aprendi foi buscando, praticando. Só quando fiz mestrado em educação compreendi a relevância desse recurso pedagógico. (PESQUISA DE CAMPO - ENTREVISTA - 22/10/2019).

O planejamento das aulas ministradas nos diferentes níveis de ensino deve ser pensado com intencionalidade para fomentar a aprendizagem dos alunos e a utilização dos recursos pedagógicos como o filme abre possibilidade para que isso aconteça. Porém, faz-se necessário encontrar caminhos para explorar além dos conteúdos curriculares as mensagens, os códigos, as várias questões 
presentes no áudio visual para que a produção e aquisição dos conhecimentos aconteçam. Reis e Strohschoener (2018) explicam que:

não se pode ficar atrelado à disciplina em si, pois se entende que o filme pode possibilitar melhoria na forma de lidar com os alunos, já que numa sala de aula não se ensina apenas conhecimentos científicos, mas valores sociais muito importantes que serão levados para fora da escola. (REIS E STROHSCHOENER, 2018, p. 1).

Partindo da exposição dos autores, os filmes não podem ser inseridos nas aulas como ferramentas no sentido puramente técnico somente para o cumprimento do currículo. Nesse sentido Bulgraen (2010) fala que

o professor deve se colocar como ponte entre o estudante e o conhecimento para que, dessa forma, o aluno aprenda a "pensar" e a questionar por si mesmo e não mais receba passivamente as informações como se fosse um depósito do educador. (BULGRAEN, 2010, p. 31).

Vale ressaltar que a formação do professor Paulo foi concluída há 14 anos, nesse período segundo pesquisas científicas a educação tradicional ainda era muito forte em universidades públicas e privadas do Brasil, Vale ressaltar que a formação do professor Paulo, foi concluída há 14 anos. Por vezes, alguns professores tendem a reproduzir em suas práticas diárias, atitudes e ações de seus antigos professores da formação inicial. Fizemos a mesma pergunta para a outra entrevistada: - as produções cinematográficas fizeram parte de sua formação inicial? A professora Clara responde:

Terminei a licenciatura em pedagogia no ano 2005 e os professores da maioria das disciplinas utilizavam dentre outros recursos pedagógicos os filmes de comédia, românticos, políticos entre outros em suas práticas docentes. Antes da exposição tinham o hábito de dialogar sobre nossas impressões. O que é engraçado é que vários desses filmes eu já tinha assistido, mas só prestava atenção no mocinho, no bandido, no romance que por vezes eram trazidos no enredo. Depois de assistir novamente quando os professores começavam a dialogar sobre a interculturalidade, as questões políticas, ideológicas, raciais e de gênero presentes fazendo a ligação com nossa formação ficava por vezes constrangida por não ter tido essa visão mais ampla. (PESQUISA DE CAMPO - ENTREVISTA 26/10/2019).

Percebo que a graduação da professora Clara é concluída um ano depois da graduação do professor Paulo, formações completamente opostas, uma técnica outra mais abrangente onde os professores correlacionavam os filmes exibidos em sala de aula com problemas atuais da sociedade, do cotidiano escolar.

Analisando a fala da docente Clara ficou evidente como a utilização desse recurso pedagógico contribuiu com o processo crítico/reflexivo na sua formação inicial, pois ao se sentir constrangida após os debates entende-se que houve uma desconstrução para posteriormente (re)construção de novos conhecimentos, tornando-se um momento rico, de interação, onde é possível 
perceber um planejamento, um objetivo e uma intencionalidade na prática do professor. Varani e Chalun (2008, p. 6), pontuam que "é neste aspecto que gostaríamos de nos fixar, na valorização de outras linguagens no trato teórico-metodológico da formação de professores".

No dialogo com os professores revelei que a frequência com que eles utilizavam os filmes em suas atividades pedagógicas tinha provocado em mim inquietações que me levaram a desenvolver a pesquisa. Diante do contexto, queria saber; quais critérios são aplicados para a utilização das produções audiovisuais em sala de aula? O professor Paulo respondeu:

\begin{abstract}
Os filmes são escolhidos de acordo com os conteúdos cuticulares que serão trabalhados, para abrir possibilidades de futuros debates acerca de conflitos presentes em sala de aula e como meio de proporcionar cultura a quem não tem condições de acesso. Percebi com essa prática que a aprendizagem ocorre com mais facilidade e a interação aumenta. Atuo em uma escola onde a cultura indígena é muito presente pelas diversas aldeias localizadas ao redor do município, tenho vários alunos indígenas, mas a escola é urbana. Ocorre o choque cultural, social e econômico gerando conflitos e práticas discriminatórias contra esses alunos. Utilizo os filmes para trabalhar a equidade, a diversidade, a inclusão, o respeito à vida, a condição humana. A educação é um direito de todos independente de cor, etnia ou classe social. (PESQUISA DE CAMPO - ENTREVISTA - 22/10/2019).
\end{abstract}

A fala do professor Paulo revela sua preocupação em atender as pautas sobre os componentes curriculares para a formação escolar que é tão relevante quanto à formação cultural dos alunos. Formar sujeitos por meio de práticas intencionais é uma das funções sociais do professor, mas, é preciso ter ciência para qual sociedade, para qual prática social, esse é o sentido da ação educativa.

Repetimos a mesma pergunta para a outra entrevistada: quais critérios são aplicados para a utilização das produções audiovisuais em sala de aula? A professora Clara respondeu:

\footnotetext{
Quando incluo um filme em minhas atividades pedagógicas penso na escolha de uma maneira bem abrange que vai desde a sua contribuição para a aprendizagem até despertar nos alunos um olhar mais humano para os estudantes deficientes, criando possibilidades de que além do acesso, possam sentir-se incluídos nas interações estimulando-os a prosseguirem nos estudos. (PESQUISA DE CAMPO - ENTREVISTA - 26/10/2019).
}

Faz-se necessário que o professor tenha compreensão da dimensão das relações vividas diaa-dia no espaço escolar por sujeitos multiculturais, sociais que defendem ideais e valores diferentes. A escola não pode ser entendida apenas como um lugar formal onde crianças, jovens e adultos o frequentam apenas para aprender a ler, a resolver as operações básicas da matemática, a escola é um espaço de socialização, de formação para a cidadania, respeito aos saberes, as diferenças, sejam elas quais forem.

Compreendo que numa visão ampla a função social do professor é entendida por meio “da relação trabalho e educação, da sua conexão com o todo social, para além da estrita função de ensino". Não pode haver função docente desvinculada da ação dos homens e mulheres que atuam 
nessa profissão, um "exercício profissional, mas também humano. Educação e trabalho, como atividade produtora da vida", para a vida (SILVA, 2004, p. 2). È fundamental que a formação escolar aconteça de maneira interdisiciplinar, formando os alunos também para o exercício da cidadania.

\section{Considerações Finais}

Conforme a coleta de dados realizada por meio das interlocuções constatou-se que foram utilizados filmes de gêneros variados (comédia, romântico, documentário entre outros) na formação inicial e continuada dos professores que foram sujeitos da pesquisa. Compreendi que os conhecimentos teóricos pertinentes que não foram alcançados por um dos docentes na formação inicial para a utilização desse recurso pedagógico em sala de aula com embasamento teórico, foram construídos no exercício da profissão e aprofundados no mestrado em educação.

Foi possível observar que a utilização de produções cinematográficas na formação inicial dos professores trouxe implicações positivas, uma vez que esse recurso didático-pedagógico é frequentemente utilizado por esses docentes com objetivos previamente traçados, com intencionalidade.

Ao analisar os critérios de inclusão dos filmes, pelos professores sujeitos da pesquisa, em suas práticas pedagógicas cotidianas, é possível afirmar que atendem diretamente as diretrizes curriculares, a resolução de conflitos, para fomentar o processo de ensino/aprendizagem, como meio de proporcionar acesso a cultura dos estudantes, a inclusão social, tornando as aulas mais interativas.

Essa tomada de decisão segundo os docentes, desperta nos alunos a reflexão crítica sobre questões como a inclusão de alunos deficientes, a diversidade de etnias e classes sociais, buscando evitar discriminações e comportamentos desumanos, contribuindo para a transformação da realidade vivenciada pelos alunos e da sociedade na qual estão inseridos.

\section{Referências}

BUGRAEN, Vanessa C. O papel do professor e sua mediação nos processos de elaboração do conhecimento. Revista Conteúdo, Capivari, v.1, n.4, ago./dez. 2010. Disponível em: http://www.moodle.cpscetec.com.br/capacitacapos/mstech/pdf/d3/aula04/FOP_d03_a04_t07b.pdf. Acesso em: 23 abr. 2020.

FRESQUET, Adriana. Cinema e educação: reflexões e experiências com profesores e estudantes de educação básica, dentro e "fora" da escola. Belo Horizonte: Autêntica, 2013.

LIMA, Maria Socorro Lucena; NAKAMOTO, Pérsio. O bom professor nos filmes. In: LIMA, Maria Socorro Lucena (Org.). A hora da prática. Fortaleza: Demócrito Rocha, 2001, v. único, p. 74-80. Disponível em:http://www.uece.br/endipe2014/ebooks/livro1/271- 
$\% 20$ FORMA $\%$ C3\%87\%C3\%83O $\% 20$ (CULTURAL) $\% 20$ DO-

CENTE $\% 20$ A $\% 20 I N O V A \% C 3 \% 87 \% C 3 \% 83$ O $\% 20 \% 20 D O \% 20 C I N E M A . p d f$. Acesso: 14 mai. 2020.

MANZINI, E. J. Entrevista semi-estruturada: análise de objetivos e de roteiros. Unesp. Marilia, 2003.

MINAYO, M.C. de S. (Org.) Pesquisa social: teoria, método e criatividade. 21 ed. Rio de Janeiro: Vozes, 2002.

SILVA, Roseli Pereira. Cinema e educação. São Paulo: Cortez, 2007.

SILVA, Geraldo Magela de Oliveira. Formação (cultural) docente: a inovação do cinema. Didática e Prática de Ensino na relação com a Escola. Educere. Livro 1. P. 2367-2377, 2014. Disponível em: http://www.uece.br/endipe2014/ebooks/livro1/271$\% 20 \mathrm{FORMA} \% \mathrm{C} 3 \% 87 \% \mathrm{C} 3 \% 83 \mathrm{O} \% 20$ (CULTURAL) $\% 20 \mathrm{DO}-$

CENTE $\% 20$ A $\% 20$ INOVA $\%$ C3\%87\%C3\%83O\%20\%20DO\%20CINEMA.pdf. Acesso: 25 jun. 2020.

PIMENTA, Selma Garrido. Saberes pedagógicos e atividade docente. 6. ed. São Paulo: Cortez, 2008.

REIS, Erisnaldo Francisco; Strohschoen Andreia Aparecida Guimarães Strohschoen. Filmes na sala de aula como estratégia pedagógica para aprendizagem ativa. Revista Educação Pública. p. 15. 2018. Disponível em: https://educacaopublica.cecierj.edu.br/artigos/18/15/filmes-na-sala-deaula-como-estratgia-pedaggica-para-aprendizagem-ativa. Acesso em: 24 abr. 2020.

VARANI, Adriana; CHALUN, Laura Noemi, Chalun. Educação Temática Digital, Campinas, v.10, n.1, p.1-23, dez. 2008. Disponível em: https://periodicos.sbu.unicamp.br/ojs/index.php/etd/article/view/1013. Acesso em: 24 mai. 2020. 